\title{
Medical Equipment Company Technician or Representative
}

National Cancer Institute

\section{Source}

National Cancer Institute. Medical Equipment Company Technician or Representative. NCI Thesaurus. Code C53442.

A trained person who is delegated by medical equipment manufacturer to provide technical advice and assistance concerning the routine maintenance and service of equipment produced by the company. 